in vivo 35 : $937-945(2021)$

doi:10.21873/invivo.12334

\title{
Risk Factors Associated With Complications After Unilateral Immediate Breast Reconstruction: A French Prospective Multicenter Study
}

\author{
JACQUES DAUPLAT $^{1}$, EMILIE THIVAT ${ }^{1}$, PHILIPPE ROUANET ${ }^{2}$, EMMANUEL DELAY ${ }^{3}$, \\ KRISHNA CLOUGH ${ }^{4}$, JEAN-LUC VERHAEGHE $^{5}$, INES RAOUST ${ }^{6}$, MARIE BANNIER ${ }^{7}$, \\ PERIG LEMASURIER ${ }^{8}$, CHRISTOPHE POMEL ${ }^{1}$ and the STIC-RMI Working Group* \\ ${ }^{1}$ Centre Jean Perrin, Clermont Ferrand, France; \\ ${ }^{2}$ Institut du Cancer de Montpellier, Val d'Aurelle, Montpellier, France; \\ ${ }^{3}$ Centre Léon Bérard, Lyon, France; \\ ${ }^{4}$ Institut du Sein, Paris, France; \\ ${ }^{5}$ Institut de Cancérologie de Lorraine-Alexis Vautrin, Vandoeuvre-lès-Nancy, France; \\ ${ }^{6}$ Centre Antoine Lacassagne, Nice, France; \\ ${ }^{7}$ Institut Paoli-Calmettes, Marseille, France; \\ ${ }^{8}$ Institut Curie, Centre René Huguenin, Saint Cloud, France
}

\begin{abstract}
Background/Aim: For women who have undergone a mastectomy, breast reconstruction provides psychological as well as aesthetic benefits. Thus, many patients ask for an immediate breast reconstruction (IBR). The present study focuses on risk factors assiociated with complications after IBR. Patients and Methods: A national prospective study (2007-2009) was conducted on 404 patients who underwent an unilateral IBR: 205 implants alone (IA) including 46 tissue expanders, 91 latissimus dorsi musculocutaneous flaps with implant (LDI), 78 autologous latissimus dorsi musculo-
\end{abstract}

This article is freely accessible online.

*STIC-RMI working group: J. Afonso, C. Abrial, G. Houvenaeghel, G. Body, M. Baron, C. Bergzoll, M.P. Chauvet, J.M. Classe, I. Cothier-Savey, M. Dejode, P. Dessogne, V. Doridot, X. Durando, A. Faucher, C. Faure, A. Figl, A. Fitoussi, B. Flipo, E. Fondrinier, J.R. Garbay, P.L. Giacalone, P. Gimbergue, F. Guillemin, M. Gutowski, J.L. Houpeau, C. Inguenault, J. Dupont Kemfang, F. Kwiatkowski, E. Lambaudie, L. Lantieri, G. Le Bouedec, C. Lepage, C. Loustalot, J.C. Machiavello, A. Mourregot, C. Nos, P.O. Paradol, F. Rimareix, J.F. Rodier, R. Rouzier, B. Saint-Aubert, R.J. Salmon, C. Scherer, Toussoun, Tunon de Lara, S. Uzan, H. Veyssière, D. Weitbruch.

Correspondence to: Christophe Pomel, Centre Jean Perrin, 58 rue Montalembert, 63011 Clermont Ferrand, France. Tel: +33 0473278121, e-mail: christophe.Pomel@clermont.unicancer.fr

Key Words: Breast cancer, breast reconstruction, complications, morbidity, mastectomy, risk factors. cutaneous flaps (LD), and 30 autologous transverse rectus abdominis musculocutaneous flaps (TRAM). Outcomes concerned major and minor complications, as well as early and late complications. Results: Related risks of complications were different according to the IBR technique. Major complications rate remained moderate and concerned $15 \%$ of patients. Obesity and diabetes significantly increased the incidence of major complications. Conclusion: To reduce complication rate, the risk factors associated with each type of IBR should be taken into account.

With the development of breast screening programs, oncoplastic surgery and associated conservative treatment, the rate of mastectomy has stabilized at around 30\% of breast cancer surgery during the last decade (1). Nowadays, immediate breast reconstruction (IBR) after mastectomy appears as an acceptable choice for patients. Thus, patients ask for an IBR to reduce the psychological and aesthetic impact of the surgery (2).

Therefore, IBR after mastectomy is increasingly proposed at the time of breast cancer treatment (3-6). A large variety of complication rates after IBR have been described in the literature (7-14). These variations could be in part explained by the various definitions of the complications considered and by the type of complication. However, authors mainly agree about the definition of major complications - defined as complications that require re-hospitalization and/or reintervention. Literature is also heterogeneous on several criteria such as the IBR procedures taken into account, the prospective or retrospective collection of data, sample sizes, 
and indications for IBR. In a prospective analysis of 404 women treated by mastectomy plus unilateral IBR, the present article focuses on surgical complications risk factors.

\section{Patients and Methods}

Patients. Between July 2007 and August 2009, 404 were treated by mastectomy plus unilateral IBR and were prospectively included in STIC-RMI trial (15). STIC-RMI study was an observational, nonrandomized, prospective trial, conducted in 22 French public and private hospitals and approved by the local ethic committee ( ${ }^{\circ}$ IDRCB 2007-A00633-50).

Inclusion criteria corresponded to standard indications for mastectomy. Patients with inflammatory breast cancers, bilateral cancers, metastatic cancers, another concurrent cancer and riskreducing prophylactic mastectomies were excluded.

Methods. Complications were recorded prospectively for each patient over a one-year follow-up period and were classified into two groups: early complications and late complications. Early complications were described as complications that occurred during hospitalization and 8 weeks after leaving the hospital. Late (or delayed) complications corresponded to complications that occurred between 3 and 6 months and then at 12 months after surgery. Complications reporting concerned the intervention sites (breast/axilla operated on and flap donor site) and included: hematoma, seroma/lymphocele, wound infection, wound dehiscence, skin-edge necrosis, flap necrosis, implant excision, re-hospitalization for surgical re-intervention or medical complication, pain and functional sequelae. Using a visual analogic scale, pain was assessed on the third-day post-surgery, on the day of departure and during the follow-up consultations (8 weeks, 3-6 months and 12 months).

We also distinguished minor and major complications. As suggested in literature, major complications were defined as complications causing a re-hospitalization or a re-operation during hospitalization.

Statistical analysis. Statistical analyses were mostly descriptive. Relationships between pairs of variables (complications by IBR type, risk factors) were tested. $\mathrm{Chi}^{2}$ tests were used for categorical data (or Fisher's exact test if class sizes were too small), and Student $t$-test or one-way ANOVA were performed when one of the two variables was numerical (or non-parametric tests - MannWhitney $U$-test or Kruskal-Wallis $H$ tests if distributions were not Gaussian or homoscedastic). Logistic regression was used for multivariate analysis of risk factors associated with major complications. Tests were two-sided and standard $p$-values $\leq 0.05$ were considered significant. SEM statistical software was used to perform statistical calculations and to manage data (16).

\section{Results}

Patients' characteristics. Patients and tumors characteristics are described in Table I. Mean patient age was 53.9 \pm 9.5 years [28-83]. $28 \%$ of patients were overweight and $18 \%$ were smokers. Approximately, $35 \%$ of patients presented with non-palpable tumors (T0) and $86 \%$ with clinical negative axilla. IBR indications following mastectomy included diffuse carcinoma in-situ in $44 \%(n=176)$, invasive carcinoma not accessible to conservative surgery in $33 \%$ $(n=132)$, ipsilateral recurrence after conservative treatment in $23 \%(n=94)$ and phyllodes tumors in $0.5 \%(n=2)$.

Treatments and techniques. Immediate breast reconstruction was performed in 404 patients. Implant alone (IA) were performed in 205 patients (51\%) (46 with tissue expander), latissimus dorsi musculocutaneous flaps with implant (LDI) in 91 patients (23\%), autologous latissimus dorsi musculocutaneous flaps (LD) in 78 patients (19\%), and autologous transverse rectus abdominis musculocutaneous (TRAM) flaps or deep inferior epigastric perforators (DIEP) flaps in 30 patients (7\%). A skin-sparing mastectomy was performed in 184 patients (46\%) whereas $15(4 \%)$ underwent nipple sparing surgery (4\%). Concurrent axillary surgery consisted of a sentinel lymph node biopsy in 67 patients $(17 \%)$ and axillary lymph node dissection in 134 patients $(33 \%)$. Table II exhibits pre- and post-surgery treatments performed according to IBR type.

Risk factors associated with complications. During the 1-year follow-up period, major complication rate reached $18.6 \%$ and concerned 60 patients, i.e. $15 \%$ of patients (patients rehospitalized/re-operated at least once), i.e. 75 re-admissions. Most of these complications (10\%) occurred within the first two months after surgery compared to the remaining period; major complications represented only $8 \%$ of reconstructions. Our analysis focused on the following risk factors for complications: patient's age at surgery, personal history (diabetes, smoking, and overweight/obesity), previous relapse, adjuvant treatments, and the type of reconstruction.

Univariate analysis of risk factors associated with complications. In the univariate analysis, we showed that rates and types of complications differed according to the surgical techniques performed for IBR (Table III). Each IBR type induces specific complications. Thus, early complications occurred in $28 \%$ of IA, $65 \%$ of LD, $67 \%$ of LD and $53 \%$ of TRAM. Implant removal was necessary in $5 \%$ of IA and $2 \%$ of LDI. Necrosis was total in 1 LD and partial in 9 TRAM (27\%). Late complications occurred, respectively, at 6 and 12 months in $25 \%$ and $18 \%$ for IA, $40 \%$ and $24 \%$ for LDI, $50 \%$ and $32 \%$ for LD, $50 \%$ and $37 \%$ for TRAM. Major complications occurred in $15 \%$ of patients: $18 \%$ in IA, $9 \%$ in LDI and LD, and $30 \%$ in TRAM. Overall, 13 IBR failures occurred (3\%).

Patients older than 55 years presented an increased risk of early complications during the first 8 weeks $(p=0.022)$, especially for complications such as lymphocele/seroma (at the breast: $p=0.049$, at the donor site: $p=0.017$ ).

During hospitalization, overweight [body mass index $(\mathrm{BMI}) \geq 25 \mathrm{~kg} / \mathrm{m}^{2}$ and $\left.<30 \mathrm{~kg} / \mathrm{m}^{2}\right] /$ obese $\left(\mathrm{BMI} \geq 30 \mathrm{~kg} / \mathrm{m}^{2}\right.$ ) 
Table I. Patients and tumor characteristics.

\begin{tabular}{|c|c|c|c|c|c|}
\hline & $\begin{array}{l}\text { Total } \\
(\mathrm{N}, \%)\end{array}$ & $\begin{array}{c}\text { Prosthesis } \pm \\
\text { expander }(\mathrm{N}, \%)\end{array}$ & $\begin{array}{l}\text { Dorsi flap } \\
(\mathrm{N}, \%)\end{array}$ & $\begin{array}{c}\text { Dorsi flap+ } \\
\text { prosthesis }(\mathrm{N}, \%)\end{array}$ & $\begin{array}{l}\text { TRAM } \\
(\mathrm{N}, \%)\end{array}$ \\
\hline $\mathrm{N}$ & 404 & 205 & 78 & 91 & 30 \\
\hline \multicolumn{6}{|l|}{ Age } \\
\hline$<50$ years & $172(43 \%)$ & $90(44 \%)$ & $31(40 \%)$ & $40(44 \%)$ & $11(37 \%)$ \\
\hline$[50-70]$ & $220(54 \%)$ & $107(52 \%)$ & $46(59 \%)$ & $49(54 \%)$ & $18(60 \%)$ \\
\hline$\geq 70$ & $11(3 \%)$ & $8(4 \%)$ & $1(1 \%)$ & $1(1 \%)$ & $1(3 \%)$ \\
\hline \multicolumn{6}{|l|}{ BMI } \\
\hline$<25 \mathrm{~kg} / \mathrm{m}^{2}$ & $282(70 \%)$ & $158(77 \%)$ & $55(71 \%)$ & $56(62 \%)$ & $13(43 \%)$ \\
\hline$[25-30]$ & $92(23 \%)$ & $35(17 \%)$ & $16(21 \%)$ & $28(31 \%)$ & $13(43 \%)$ \\
\hline$\geq 30$ & $25(6 \%)$ & $9(4 \%)$ & $7(9 \%)$ & $5(5 \%)$ & $4(13 \%)$ \\
\hline \multicolumn{6}{|l|}{ Menopause } \\
\hline No & $201(50 \%)$ & $103(50 \%)$ & $39(50 \%)$ & $46(51 \%)$ & $13(43 \%)$ \\
\hline Yes & $187(46 \%)$ & $91(44 \%)$ & $35(45 \%)$ & $44(48 \%)$ & $17(57 \%)$ \\
\hline \multicolumn{6}{|l|}{ Smoking } \\
\hline No & $330(82 \%)$ & $162(79 \%)$ & $68(87 \%)$ & $71(78 \%)$ & $29(97 \%)$ \\
\hline Yes & $72(18 \%)$ & $42(20 \%)$ & $10(13 \%)$ & $19(21 \%)$ & $1(3 \%)$ \\
\hline \multicolumn{6}{|l|}{ Diabetes } \\
\hline No & $390(97 \%)$ & $197(96 \%)$ & $76(97 \%)$ & $89(98 \%)$ & $28(93 \%)$ \\
\hline Yes & $10(2 \%)$ & $6(3 \%)$ & $2(3 \%)$ & $1(1 \%)$ & $1(3 \%)$ \\
\hline \multicolumn{6}{|l|}{ Previous surgery } \\
\hline Thoracic & $24(6 \%)$ & $11(5 \%)$ & $2(3 \%)$ & $8(9 \%)$ & $3(10 \%)$ \\
\hline Abdominal & $214(53 \%)$ & $106(52 \%)$ & $44(56 \%)$ & $50(55 \%)$ & $14(47 \%)$ \\
\hline \multicolumn{6}{|l|}{ Clinical size } \\
\hline T0 & $140(35 \%)$ & $66(32 \%)$ & $42(54 \%)$ & $26(29 \%)$ & $6(20 \%)$ \\
\hline $\mathrm{T} 1$ & $72(18 \%)$ & $30(15 \%)$ & $11(14 \%)$ & $23(25 \%)$ & $8(27 \%)$ \\
\hline $\mathrm{T} 2$ & $54(13 \%)$ & $24(12 \%)$ & $11(14 \%)$ & $13(14 \%)$ & $6(20 \%)$ \\
\hline $\mathrm{T} 3$ & $10(2 \%)$ & $4(2 \%)$ & $0(0 \%)$ & $4(4 \%)$ & $2(7 \%)$ \\
\hline $\mathrm{T} 4$ & $0(0 \%)$ & $0(0 \%)$ & $0(0 \%)$ & $0(0 \%)$ & $0(0 \%)$ \\
\hline Tis & $116(29 \%)$ & $75(37 \%)$ & $12(15 \%)$ & $22(24 \%)$ & $7(23 \%)$ \\
\hline $\mathrm{TX}$ & $4(1 \%)$ & $1(0 \%)$ & $1(1 \%)$ & $1(1 \%)$ & $1(3 \%)$ \\
\hline \multicolumn{6}{|l|}{ Clinical N } \\
\hline No & $348(86 \%)$ & $177(86 \%)$ & $69(88 \%)$ & $74(81 \%)$ & $28(93 \%)$ \\
\hline N1 & $19(5 \%)$ & $5(2 \%)$ & $5(6 \%)$ & $8(9 \%)$ & $1(3 \%)$ \\
\hline $\mathrm{N} 2$ & $1(0 \%)$ & $0(0 \%)$ & $0(0 \%)$ & $1(1 \%)$ & $0(0 \%)$ \\
\hline $\mathrm{Nx}$ & $28(7 \%)$ & $18(9 \%)$ & $3(4 \%)$ & $6(7 \%)$ & $1(3 \%)$ \\
\hline \multicolumn{6}{|l|}{ Histology } \\
\hline Invasive or mixed & $194(48 \%)$ & $82(40 \%)$ & $40(51 \%)$ & $52(57 \%)$ & $20(67 \%)$ \\
\hline In-situ & $205(51 \%)$ & $120(59 \%)$ & $37(47 \%)$ & $39(43 \%)$ & $9(30 \%)$ \\
\hline Other & $5(1 \%)$ & $3(1 \%)$ & $1(1 \%)$ & $0(0 \%)$ & $1(3 \%)$ \\
\hline \multicolumn{6}{|l|}{ Relapse } \\
\hline No & $310(77 \%)$ & $171(83 \%)$ & $61(78 \%)$ & $62(68 \%)$ & $16(53 \%)$ \\
\hline Yes & $94(23 \%)$ & $34(17 \%)$ & $17(22 \%)$ & $29(32 \%)$ & $14(47 \%)$ \\
\hline \multicolumn{6}{|l|}{ Indication of mastectomy } \\
\hline Diffuse in situ & $203(50 \%)$ & $118(58 \%)$ & $37(47 \%)$ & $43(47 \%)$ & $5(17 \%)$ \\
\hline Invasive not operable & $53(13 \%)$ & $28(14 \%)$ & $8(10 \%)$ & $12(13 \%)$ & $5(17 \%)$ \\
\hline Multifocal & $76(19 \%)$ & $35(17 \%)$ & $16(21 \%)$ & $20(22 \%)$ & $5(17 \%)$ \\
\hline Non in sano conserv. & $129(32 \%)$ & $67(33 \%)$ & $32(41 \%)$ & $23(25 \%)$ & $7(23 \%)$ \\
\hline Ipsilateral relapse & $94(23 \%)$ & $34(17 \%)$ & $17(22 \%)$ & $29(32 \%)$ & $14(47 \%)$ \\
\hline Phyllodes tumor & $2(0 \%)$ & $2(1 \%)$ & $0(0 \%)$ & $0(0 \%)$ & $0(0 \%)$ \\
\hline
\end{tabular}

women had a higher rate of complications, notably in the breast ( $p=0.001)$ and locally, including axilla $(p=0.05)$. This finding was also observed during the first 8 weeks [ $p=0.00007$, overweight: $\mathrm{RR}=1.4(1.1-1.7)$, obese: $\mathrm{R} \mathrm{R}=1.6$ (1.1-2.3)], particularly considering wound dehiscence $[p=0.019, \mathrm{RR}=2.7(1.2-6.0)]$ and local pain $[p=0.006$, overweight: $\mathrm{RR}=2.3$ (1.0-5.4), obese: $\mathrm{RR}=3.9$ (1.3-12.0)]. Surgical site infections were more frequent in obese patients [ $p=0.0012, \mathrm{RR}=9.0(2.8-28.5)]$, but not significantly for overweight patients. At 3-6 months and 1 year, obesity 
Table II. Pre- and post-surgical treatments [percentages correspond to the proportion of treatments realized per immediate breast reconstruction (IBR) procedure]. Note: Several prior treatments may have been administered to a single patient.

\begin{tabular}{|c|c|c|c|c|c|}
\hline & $\begin{array}{l}\text { Total } \\
(\mathrm{N}, \%)\end{array}$ & $\begin{array}{c}\text { Prosthesis } \pm \\
\text { expander }(\mathrm{N}, \%)\end{array}$ & $\begin{array}{l}\text { Dorsi flap } \\
(\mathrm{N}, \%)\end{array}$ & $\begin{array}{c}\text { Dorsi flap+ } \\
\text { prosthesis }(\mathrm{N}, \%)\end{array}$ & $\begin{array}{l}\text { TRAM } \\
(\mathrm{N}, \%)\end{array}$ \\
\hline \multicolumn{6}{|l|}{ Prior treatments } \\
\hline Conservative surgery & $249(62 \%)$ & $117(57 \%)$ & $50(64 \%)$ & $60(66 \%)$ & $22(73 \%)$ \\
\hline Chemotherapy & $82(20 \%)$ & $28(14 \%)$ & $13(17 \%)$ & $29(32 \%)$ & $12(40 \%)$ \\
\hline Target treatment & $15(4 \%)$ & $4(2 \%)$ & $3(4 \%)$ & $5(5 \%)$ & $3(10 \%)$ \\
\hline Hormonotherapy & $44(11 \%)$ & $15(7 \%)$ & $5(6 \%)$ & $19(21 \%)$ & $5(17 \%)$ \\
\hline Radiotherapy & $104(26 \%)$ & $30(15 \%)$ & $17(22 \%)$ & $41(45 \%)$ & $16(53 \%)$ \\
\hline \multicolumn{6}{|c|}{ Post-mastectomy treatments } \\
\hline None & $205(51 \%)$ & $114(56 \%)$ & $43(55 \%)$ & $38(42 \%)$ & $10(33 \%)$ \\
\hline Chemotherapy & $61(15 \%)$ & $28(14 \%)$ & $11(14 \%)$ & $12(13 \%)$ & $10(33 \%)$ \\
\hline Targeted treatment & $27(7 \%)$ & $14(7 \%)$ & $5(6 \%)$ & $5(5 \%)$ & $3(10 \%)$ \\
\hline Hormonotherapy & $160(40 \%)$ & $71(35 \%)$ & $28(36 \%)$ & $47(52 \%)$ & $14(47 \%)$ \\
\hline Radiotherapy & $42(10 \%)$ & $20(10 \%)$ & $11(14 \%)$ & $6(7 \%)$ & $5(17 \%)$ \\
\hline
\end{tabular}

Table III. Synthesis of complications according to the immediate breast reconstruction (IBR) technique. Early complications occurred during hospitalization and 8 weeks after leaving the hospital. Complications occurring between 3 and 6 months, and then, at 12 months after surgery were defined as late complications. Major complications were defined as complications causing a re-hospitalization, or a re-operation during hospitalization.

\begin{tabular}{|c|c|c|c|c|}
\hline & $\begin{array}{l}\text { Single implant } \\
\qquad \mathrm{N}=205\end{array}$ & $\begin{array}{l}\text { Dorsi flap+implant } \\
\mathrm{N}=91\end{array}$ & $\begin{array}{l}\text { Autologous dorsi Flap } \\
\qquad \mathrm{N}=78\end{array}$ & $\begin{array}{l}\text { TRAM and DIEP } \\
\qquad \mathrm{N}=30\end{array}$ \\
\hline Hospitalization stay (days) & $7.1 \pm 2.2$ & $8.8 \pm 2.8$ & $8.5 \pm 4.6$ & $9.6 \pm 2.9$ \\
\hline \multicolumn{5}{|l|}{ Early complications } \\
\hline During hospitalization & $7 \%$ & $16 \%$ & $17 \%$ & $30 \%$ \\
\hline \multirow[t]{5}{*}{ During the first 8 weeks } & $28 \%$ & $65 \%$ & $67 \%$ & $53 \%$ \\
\hline & Collections & Collections & Collections & Partial \\
\hline & Infections & Dorsal (46\%) & Dorsal (44\%) & necrosis \\
\hline & 10 implants & 2 implants & 1 total necrosis & $(27 \%)$ \\
\hline & removal $(5 \%)$ & removal $(2 \%)$ & of the flap & \\
\hline \multicolumn{5}{|l|}{ Late complications } \\
\hline 3 to 6 months & $25 \%$ & $40 \%$ & $50 \%$ & $50 \%$ \\
\hline \multirow[t]{5}{*}{6 to 12 months } & $18 \%$ & $24 \%$ & $32 \%$ & $37 \%$ \\
\hline & Pain $(20 \%)$ & Pain & Pain & Pain \\
\hline & Shoulder limitation (13\%) & Shoulder and & Shoulder and & Thorax and \\
\hline & 1 implant change & back & back & abdomen \\
\hline & $\begin{array}{l}1 \text { removal then dorsi-flap } \\
\text { reconstruct }\end{array}$ & & & \\
\hline Major complications & $18 \%$ & $9 \%$ & $9 \%$ & $30 \%$ \\
\hline
\end{tabular}

appeared to be related to lymphedema occurrence [3-6 months: $p=0.001, \mathrm{RR}=11.4(3.2-39.7) ; 1$ year: $p=0.005$, $\mathrm{RR}=12.4$ (2.7-56.2)]. Overall, surgical revisions and readmissions for medical complications were more frequent when BMI was $>25(p=0.01)$. In the obese women group, the revision risk was multiplied by $2.6(1.5-4.3)(p=0.00042)$, and the risk for re-hospitalization by $4.3(1.7-11.2)(p=0.012)$.

Moreover, pain sequelae frequency was higher in smokers ( $p=0.029$ at $3-6$ months, and $p=0.015$ at 12 months), and appeared mainly at the breast and thorax. No association was evidenced between smoking and the flap or between skin edges necrosis and healing difficulties.

During the 12-months follow-up, the frequency of reinterventions and/or readmission for medical or surgical complications was higher in diabetic than in non-diabetic patients $(50 \%$ vs. 14\%, $p=0.006)$. However, the infection risk was not increased by diabetes. During the first 8 weeks, wound dehiscence tended to be higher in diabetics $(40 \% \mathrm{vs}$. 


\begin{tabular}{|c|c|c|c|}
\hline Parameters & Encoding & \begin{tabular}{|c|c|} 
& Forest plot of Odds-Ratios \\
$0 \ldots$ & 1
\end{tabular} & Odds-Ratios [95\%-Cl] \\
\hline \multirow{3}{*}{$\begin{array}{l}\text { IBR Type } \\
\text { (ref. auto. dorsi flap) }\end{array}$} & $1=\mathrm{DF}+\mathrm{implant}$ & $\longmapsto$ & $1.69[1.19-2.41]$ \\
\hline & $2=$ implant & 1 & $2.86[1.41-5.83]$ \\
\hline & $3=$ TRAM & 1 & $4.85[1.67-14.08]$ \\
\hline \multirow[t]{2}{*}{ Body mass index } & $1=[25-30[$ & 1 & $1.66[1.03-2.65]$ \\
\hline & $2=[30$ and +$]$ & & $2.74[1.07-7.02]$ \\
\hline Diabetes & $1=Y e s$ & & $4.60[1.09-19.51]$ \\
\hline Tobacco & $1=$ Yes & & $1.87[0.90-3.89]$ \\
\hline Conserving surgery & $1=$ Yes & 4 & $0.57[0.27-1.18]$ \\
\hline Adjuvant radioth. & $1=$ Yes & & $1.99[0.74-5.36]$ \\
\hline Relapse & $1=Y e s$ & & $1.71[0.55-5.28]$ \\
\hline Adjuvant chemoth. & $1=Y e s$ & $\mapsto$ & $0.80[0.34-1.86]$ \\
\hline Previous radioth. & $1=$ Yes & -1 & $0.81[0.27-2.45]$ \\
\hline Previous chemoth. & $1=$ Yes & $\longmapsto$ & $0.81[0.22-3.03]$ \\
\hline Lymphadenectomy & $1=$ Yes & 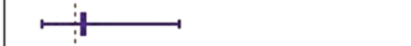 & $1.14[0.49-2.61]$ \\
\hline Age & $1=[55$ and +$]$ & $\longmapsto$ & $1.09[0.59-2.01]$ \\
\hline
\end{tabular}

Figure 1. Results of the logistic regression testing the presencelabsence of major complications occurring until 1 year of follow-up [DF+implant= dorsi flap+implant, transverse rectus abdominis musculocutaneous (TRAM) $=$ TRAM or deep inferior epigastric perforators (DIEP)].

$7 \%, p=0.07)$. Interestingly, patients who underwent an IBR after a post-conservative relapse exhibited a higher rate of breast complications during hospitalization (14\% vs. $7 \%$, $p=0.05$ ).

Axillary dissection increased lymphedema development at 3-6 months $(7 \%$ vs. 1\%,p=0.025) and 12 months $(6 \% v s$. $1 \%, p=0.043)$ after intervention. Moreover, lymphedema development was accompanied by painful sequelae in the arm at 3-6 months $(17 \%$ vs. $5 \%, p=0.004)$, in the shoulder at 1 year $(15 \%$ vs. $4 \%, p=0.008)$, and functional sequelae in the same place at 1 year $(25 \%$ vs. $7 \%, p=0.036)$. These complications cannot be attributed to the IBR. However, the assessment of exclusive sentinel lymph node biopsy did not increase the frequency of complications, compared with the population without axillary dissection.

During hospitalization, we also observed higher rates of local breast complications $(16 \%$ vs. $7 \%, p=0.01)$ and hematoma (12\% vs. $4 \%, p=0.01$ ) in relapsing patients previously treated by chemotherapy than in naïve patients. Prior chemotherapy was also associated with more frequent pain sequelae in the arm at 3-6 months (16\% vs. 6\%, p=0.04). For patients treated by preoperative (neo-adjuvant) chemotherapy, arm pain sequelae occurred more frequently at 3-6 months (16\% vs. 6\%, $p=0.04)$ as well as functional sequelae at the shoulder (15\% vs. $4 \%, p=0.032$ ) after 12 months.

A higher frequency of lymphedema at 3-6 months after surgery was associated with the administration of adjuvant chemotherapy. This result was likely due to the greater frequency of axillary dissection ( $31 \%$ vs. $14 \%, p=0.001)$ when adjuvant chemotherapy is indicated.

Finally, complications were not affected by previous radiotherapy. These results seem to contradict the increase of local complications among patients with recurrent disease, who were already treated by radiotherapy in $75 \%$ of cases. Postoperative radiotherapy was related to a higher incidence of lymphedema at 3-6 months $(8 \%$ vs. $2 \%, p=0.044)$. But this relation disappeared at 12 months. No significant association was observed between postoperative radiotherapy and necrosis (flap or skin edges) or delayed healing.

Multivariate analysis of risk factors associated with major complications. In multivariate analysis, only some factors affected independently the risk associated with major complications. We used a statistical model including only significant covariates (Figure 1). The reconstruction procedure $(p=0.0037)$ remains an important factor. Thus, IBR with TRAM corresponded to the highest risk, followed by IA and LDI. Interestingly, autologous LD were associated with the lowest risk. We also demonstrated that a prior attempt to achieve a conservative treatment reduced the risk of major complications $(p=0.018)$. Unsurprisingly, overweight and obesity $(p=0.023)$, just like diabetes $(p=0.04)$, increased the risk associated with major complications. Smoking or adjuvant radiotherapy tended to increase risks but not significantly. Neither prior radiotherapy nor prior or adjuvant chemotherapy affected the risk for major complications. 


\section{Discussion}

Complication rates after IBR vary among studies in the literature. This prospective study of 404 IBR is one of the largest studies conducted on unilateral reconstructions. Our $18.6 \%$ major complications rate is one of the lowest reported in the literature (between $12 \%$ and $37 \%)(14,17,18)$. Risk factors for complications have often been analyzed in the literature, but most often within retrospective series and with contradictory conclusions. In our prospective sample, which analyzes the risk for re-intervention/re-hospitalization in a multivariate way, only the following parameters appeared significant: the type of IBR, obesity and diabetes, and a prior attempt at conservative surgery. The latter may suggest that if conservative surgery is mandatory, patients' clinical characteristics are more favorable.

The impact of IBR procedure type on major complications has never been studied prospectively. In retrospective setting, Berry et al. (8) and Pinsolle et al. (7) observed no difference. In our study, the type of reconstruction predicted major complications, as well as early complications. These latter (during hospitalization or during the eight following weeks) are rarer with implants alone when compared with more complex reconstruction such as dorsi flap or TRAM. Monrigal et al. (9) have also found a higher risk for early complications, especially for TRAM. A retrospective analysis of a 12,129-patients database made-up from 2005 to 2011 has shown that flap IBR was associated with a higher risk of early complications than was single prosthesis IBR (adjusted $\mathrm{OR}=1.41$ ) (19).

Post-surgical infections (with or without collections) represent the major complication risk after a single-implant IBR: it induced prosthesis removal, and thus, reconstruction failure $(5 \%)$. The use of expanders seemed to increase this risk since it was multiplied by seven in our study.

Moreover, infection rates vary largely according to IBR procedures. Indeed, Alderman et al. (14) have described a 35\% maximal rate for implants or expanders alone versus $13.4 \%$ for TRAM. As Pinsolle et al. (7) have shown, implant reconstruction also induces a significantly higher infection rate.

The high percentage of post-surgical complications found with dorsi flaps is due to the collections of seroma, particularly in the dorsal region. Some surgeons try in particular to prevent seroma by quilting sutures using the Chippendale technique (20).

The postoperative risk of TRAM/DIEP concerns the necrosis of the flap and/or the skin edges (26\% in our series). It can be limited by the high technical skill of surgeon and respect of contra-indications (obesity and smoking).

Delayed complications mainly gather shoulder, arm, and donor sites pain sequelae, which can induce movement limitations. The occurrence of these phenomena is shared with axillary lymphadenectomy. They are more frequent after flap IBR $(40 \%$ to $50 \%)$ than after implant IBR $(25 \%)$, and they tend to get better with time (25\% to $35 \%$ with flap, and $20 \%$ with implants).

Several authors have described obesity as a risk factor associated with complications after breast reconstruction (7-9, $13,17,19,21-27)$. However, the BMI cut-offs used to define overweight and obesity are rather disparate. Using a multivariate analysis, overweight $\left(25 \leq \mathrm{BMI}<30 \mathrm{~kg} / \mathrm{m}^{2}\right)$ and obesity $\left(\mathrm{BMI} \geq 30 \mathrm{~kg} / \mathrm{m}^{2}\right)$ were associated with more frequent re-hospitalizations $(\times 2.6$ by overweight and $\times 4.3$ by obesity) and early complications $(\times 1.4$ and $\times 1.6$ resp.). The increased risk of major complications in relation to BMI has been evidenced in four other studies. In obese patients, McCarthy et al. (26) have found a twice higher risk for global complications after single prosthesis/expander IBR, and a 7 times-higher risk for reconstruction failure. Ducic et al. (21) observed a flap complication rates of 2.6 times-higher in obese patients after a TRAM reconstruction. We noted a higher frequency of wound dehiscence, lymphedema and implant removal in overweight or obese patients. Higher rate of infection $(\times 9)$ was also found in obese patients. Similarly, Pinsolle et al. (7) reported an infection risk multiplied by 8 for overweight or obese patients. In obese and overweight patients, IBR should be considered with much caution, and even more so when obesity coexists with other identified risk factors. In this line, Berry et al. (8) have proposed a flowchart for obese patients to pre-operatively evaluate the risk for complications.

In the present study, diabetics presented a 4.6 times-higher risk for major complications than other patients. On the opposite, several authors reported that diabetes did not increase this risk $(8,24-26,28)$. Only Berry et al. (8) reported an overall complication rate multiplied by 3 when diabetic patients are reconstructed using an expander. Infection of surgical site, caused by mammary intervention, was frequently associated with diabetes $(22,23)$, but we could not confirm this conclusion in our series $(p=0.45)$. These discrepancies are presumably related to the limited number of diabetic patients in the cited articles (4\% of IA, i.e. 10 patients in our population, from $1 \%$ to $4.4 \%$ in the literature) $(8,24-26)$. The only series containing an important proportion of diabetics (15\%) is reported by Angarita et al. (23). Cohen et al. demonstrated that diabetic patients with IBR may delay adjuvant chemotherapy initiation (29).

Our adjusted (multivariate) analysis did not evidence an increase of complications related to radiotherapy, especially if it had been carried out previously. A posterior radiotherapy seemed to double the risk, but the difference was not statistically significant. In other studies, the risk for complication with radiotherapy prescribed after IBR varies a lot $(8,14,17,30-32)$. Krueger et al. reported a higher complication rate in patients treated by prosthesis/expander IBR plus radiotherapy than in patients who didn't undergo radiotherapy ( $68 \%$ vs. $31 \%$; $p=0.006)$ (32). Berry et al. (8) 
found an increased risk for major complications $[\mathrm{OR}=5.2$ (2.4-11.2)] with adjuvant radiotherapy, but also with prior radiotherapy $[\mathrm{OR}=2.7(1.5-4.9)]$. However, women who had reconstruction using a flap underwent fewer complications than those having reconstruction by prosthesis/expander, if radiotherapy has been received prior to IBR $(p=0.005$; $\mathrm{OR}=0.22)$, as well as post-IBR $(p=0.05 ; \mathrm{OR}=0.35)$. These authors suggested that breast reconstruction using a musculocutaneous flap could be the best strategy for patients previously treated by radiotherapy.

In our series, chemotherapies prior to and/or post mastectomy+IBR were associated with local breast complications: hematoma, pain, arm or shoulder functional sequelae and lymphedema. But using adjusted analysis, these associations were not still observed because chemotherapy was often associated with lymphadenectomy. In a large series of patients who received neo-adjuvant or adjuvant chemotherapy, McCarthy et al. (26) noted no significant difference for local complications. Recently, a meta-analysis confirmed chemotherapy did not increase the complication risk after IBR (33). Monrigal et al. (9) studied a retrospective series of 210 mastectomies+IBR carried out after neo-adjuvant chemotherapy plus radiotherapy: morbidity was not increased by pre-surgical treatments. Thus, for invasive breast cancers treated with a conservative surgery, they recommend such a therapeutic sequence if there is an indication for chemotherapy and radiotherapy, and if patients are eligible for an IBR after the mastectomy to reduce onset-delays of adjuvant treatments.

We showed that smoking was not associated with a higher risk for major complications. Only two studies have reported an IBR-failure rate that was significantly superior among smokers $(26,34)$. Considering all types of complications, smoking has been described as a major risk factor in many studies $(7,12,17,19,21,24,26,31,34-36)$. In a large series of 718 TRAM reconstructions, Chang et al. (35) have found smokers had a significantly increased risk for skin-edge necrosis of mastectomy compared with non-smokers $(19 \%$ $v s .9 \%, p=0.005)$. They demonstrated that smoking confered an increased risk for musculocutaneous flap necrosis $(4.4 \%$ vs. $0.8 \% ; p=0.025)$ and hernia $(6.7 \% v s .2 .1 \%, p=0.016)$. Vega et al. (24) and Albino et al. (12) also observed this increase of necrosis risk. The frequency of infections was also augmented in several studies $(21,24,34)$.

In line with the literature, no association between age at diagnosis and risk for major complications could be evidenced in our study. Very few studies have reported that age favors complications $(17,26,37)$. However, early complications appeared to be more frequent among older patients ( $\geq 55$ years) in particular regarding lymphoceles/seroma. Pinsolle et al. (7) and Xue et al. $(7,22)$ observed a higher rate of hematoma after 50 years and a higher rate of infections, respectively. Surprisingly, a study has demonstrated a better outcome in patients over 70 years old after IBR (38).

\section{Conclusion}

IBR is a technical challenge with oncologic and esthetic issues for surgeons since morphology, patients' wishes, therapeutic sequence and risk factors for complications differ from one patient to another. The rate of major complications (re-intervention/re-hospitalization) remains moderate and concerns $15 \%$ of patients. With flap-reconstruction, the incidence of major complications was significantly increased by obesity and diabetes. The consideration of these two latter risk factors, before the surgeon decides to perform an IBR, could probably reduce the post-surgical complication rate.

\section{Conflicts of Interest}

The Authors declare that they have no conflicts of interest in relation to this study.

\section{Authors' Contributions}

Conception and design: J. Dauplat, C. Pomel ; Investigation: P. Rouanet, E. Delay, K. Clough, J-L Verhaeghe, I. Raoust, M. Bannier, P. Lemasurier, J. Dauplat, C. Pomel ; Writing-original draft preparation: E. Thivat ; All Authors made pertinent contributions to the article, and proofread and approved the final article before submission.

\section{Acknowledgements}

STIC-RMI was entirely financed by INCa (The French National Institute of Cancer) by the STIC program (support of innovative and expensive techniques) (agreement: November 2005, 17th). The funding source did not participate in study design, collection, analysis, or interpretation of the data, or writing of the report.

\section{References}

1 Rouanet P: [Current position of breast reconstruction in oncology]. Gynécologie Obstétrique Fertil 30: 985-993, 2002. PMID: 12661289.

2 Retrouvey H, Kerrebijn I, Metcalfe KA, O'Neill AC, McCready DR, Hofer SOP and Zhong T: Psychosocial functioning in women with early breast cancer treated with breast surgery with or without immediate breast reconstruction. Ann Surg Oncol 26: 2444-2451, 2019. PMID: 31062209. DOI: 10.1245/s 10434-01907251-9

3 Malata CM, McIntosh SA and Purushotham AD: Immediate breast reconstruction after mastectomy for cancer. Br J Surg 87: 1455-1472, 2000. PMID: 11091232. DOI: 10.1046/j.13652168.2000.01593.x

4 Sandelin K, Wickman M and Billgren AM: Oncological outcome after immediate breast reconstruction for invasive breast cancer: a long-term study. Breast Edinb Scotl 13: 210-218, 2004. PMID: 15177424. DOI: $10.1016 /$ j.breast.2003.10.010

5 Mustonen P, Lepistö J, Papp A, Berg M, Pietiläinen T, Kataja V and Härmä M: The surgical and oncological safety of immediate breast reconstruction. Eur J Surg Oncol J Eur Soc Surg Oncol 
Br Assoc Surg Oncol 30: 817-823, 2004. PMID: 15336725. DOI: $10.1016 /$ j.ejso.2004.06.003

6 Susini T, Renda I, Giani M, Vallario A, Nori J, Vanzi E, Innocenti A, Lo Russo $\mathrm{G}$ and Bianchi S: Changing trends in mastectomy and breast reconstruction. analysis of a singleinstitution experience between 2004-2016. Anticancer Res 39: 5709-5714, 2019. PMID: 31570471. DOI: 10.21873/anticanres. 13770

7 Pinsolle V, Grinfeder C, Mathoulin-Pelissier S and Faucher A: Complications analysis of 266 immediate breast reconstructions. J Plast Reconstr Aesthetic Surg JPRAS 59: 1017-1024, 2006. PMID: 16996422. DOI: 10.1016/j.bjps.2006.03.057

8 Berry T, Brooks S, Sydow N, Djohan R, Nutter B, Lyons J and Dietz J: Complication rates of radiation on tissue expander and autologous tissue breast reconstruction. Ann Surg Oncol 17: 202210, 2010. PMID: 20853034. DOI: 10.1245/s10434-010-1261-3

9 Monrigal E, Dauplat J, Gimbergues P, Le Bouedec G, Peyronie M, Achard JL, Chollet P, Mouret-Reynier MA, Nabholtz JM and Pomel C: Mastectomy with immediate breast reconstruction after neoadjuvant chemotherapy and radiation therapy. A new option for patients with operable invasive breast cancer. Results of a 20 years single institution study. Eur J Surg Oncol J Eur Soc Surg Oncol Br Assoc Surg Oncol 37: 864-870, 2011. PMID: 21843920. DOI: 10.1016/j.ejso.2011.07.009

10 Michy T, Gimbergues P, Le Bouëdec G and Dauplat J: [What surgical procedure for immediate breast reconstruction after preoperative radiotherapy and chemotherapy?]. J Chir (Paris) 144: 511-515, 2007. PMID: 18235363.

11 Whitfield GA, Horan G, Irwin MS, Malata CM, Wishart GC and Wilson CB: Incidence of severe capsular contracture following implant-based immediate breast reconstruction with or without postoperative chest wall radiotherapy using 40 Gray in 15 fractions. Radiother Oncol J Eur Soc Ther Radiol Oncol 90: 141147, 2009. PMID: 18977547. DOI: 10.1016/j.radonc. 2008.09.023

12 Albino FP, Koltz PF, Ling MN and Langstein HN: Irradiated autologous breast reconstructions: effects of patient factors and treatment variables. Plast Reconstr Surg 126: 12-16, 2010. PMID: 20220558. DOI: 10.1097/PRS.0b013e3181da878f.

13 Gimbergues P, Le Bouedec G, Pomel C, Janny-Peyronie M and Dauplat J: [Morbidity of the trans rectus abdominis musculocutaneous flap in breast reconstruction. Retrospective study about 125 patients]. Ann Chir 128: 310-315, 2003. PMID: 12878067.

14 Alderman AK, Wilkins EG, Kim HM and Lowery JC: Complications in postmastectomy breast reconstruction: twoyear results of the Michigan Breast Reconstruction Outcome Study. Plast Reconstr Surg 109: 2265-2274, 2002. PMID: 12045548

15 Dauplat J, Kwiatkowski F, Rouanet P, Delay E, Clough K, Verhaeghe JL, Raoust I, Houvenaeghel G, Lemasurier P, Thivat E, Pomel C and the STIC-RMI working group: Quality of life after mastectomy with or without immediate breast reconstruction. Br J Surg 104: 1197-1206, 2017. DOI: 10.1002/ bjs. 10537

16 Kwiatkowski F, Girard M, Hacene K and Berlie J: [Sem: a suitable statistical software adaptated for research in oncology]. Bull Cancer (Paris) 87: 715-721, 2000. PMID: 11084535.

17 Seth AK, Hirsch EM, Fine NA, Dumanian GA, Mustoe TA, Galiano RD, Hansen NM and Kim JYS: Additive risk of tumescent technique in patients undergoing mastectomy with immediate reconstruction. Ann Surg Oncol 18: 3041-3046, 2011. PMID: 21947584. DOI: 10.1245/s10434-011-1913-y

18 Rusby JE, Waters RA, Nightingale PG and England DW: Immediate breast reconstruction after mastectomy: what are the long-term prospects? Ann R Coll Surg Engl 92: 193-197, 2010. PMID: 20223055. DOI: 10.1308/003588410X12628812458770

19 Fischer JP, Wes AM, Tuggle CT, Serletti JM and Wu LC: Risk Analysis and Stratification of Surgical Morbidity after Immediate Breast Reconstruction. J Am Coll Surg 217: 780-787, 2013. DOI: 10.1016/j.jamcollsurg.2013.07.004

20 Gisquet H, Delay E, Paradol P-O, Toussoun G, Delaporte T and Perol D: [Prevention of seroma by quilting suture after harvesting latissimus dorsi flap. The "Chippendale" technic]. Ann Chir Plast Esthét 55: 97-103, 2010. PMID: 19679385. DOI: 10.1016/j.anplas.2009.05.002

21 Ducic I, Spear SL, Cuoco F and Hannan C: Safety and risk factors for breast reconstruction with pedicled transverse rectus abdominis musculocutaneous flaps: a 10-year analysis. Ann Plast Surg 55: 559-564, 2005. PMID: 16327450.

22 Xue DQ, Qian C, Yang L and Wang XF: Risk factors for surgical site infections after breast surgery: a systematic review and meta-analysis. Eur J Surg Oncol J Eur Soc Surg Oncol Br Assoc Surg Oncol 38: 375-381, 2012. PMID: 22421530. DOI: 10.1016/j.ejso.2012.02.179

23 Angarita FA, Acuna SA, Torregrosa L, Tawil M, Escallon J and Ruíz Á: Perioperative variables associated with surgical site infection in breast cancer surgery. J Hosp Infect 79: 328-332, 2011. PMID: 22054593. DOI: 10.1016/j.jhin.2011.08.006

24 Vega S, Smartt JM, Jiang S, Selber JC, Brooks CJM, Herrera HR and Serletti JM: 500 Consecutive patients with free TRAM flap breast reconstruction: a single surgeon's experience. Plast Reconstr Surg 122: 329-339, 2008. PMID: 18626347. DOI: 10.1097/PRS.0b013e31817f45cb

25 Mehrara BJ, Santoro TD, Arcilla E, Watson JP, Shaw WW and Da Lio AL: Complications after microvascular breast reconstruction: experience with 1195 flaps. Plast Reconstr Surg 118: 1100-1109; discussion 1110-1111, 2006. PMID: 17016173. DOI: 10.1097/01.prs.0000236898.87398.d6

26 McCarthy CM, Mehrara BJ, Riedel E, Davidge K, Hinson A, Disa JJ, Cordeiro PG and Pusic AL: Predicting complications following expander/implant breast reconstruction: an outcomes analysis based on preoperative clinical risk. Plast Reconstr Surg 121: 1886-1892, 2008. PMID: 18520873. DOI: 10.1097/PRS. 0b013e31817151c4

27 Yazar S, Altinkaya A, Bengur FB, Karadag EC, Kara H and Uras C: Factors associated with complications in immediate breast reconstruction in 1 stage with completely submuscular implants. Ann Plast Surg 83: 264-270, 2019. DOI: 10.1097/SAP.0000000 000001808

28 Aristei C, Falcinelli L, Bini V, Palumbo I, Farneti A, Petitto RP, Gori $\mathrm{S}$ and Perrucci E: Expander/implant breast reconstruction before radiotherapy. Strahlenther Onkol 188: 1074-1079, 2012. DOI: $10.1007 / \mathrm{s} 00066-012-0231-\mathrm{z}$

29 Cohen O, Lam G, Choi M, Ceradini D and Karp N: Risk factors for delays in adjuvant chemotherapy following immediate breast reconstruction. Plast Reconstr Surg 142: 299-305, 2018. PMID: 29782396. DOI: $10.1097 /$ PRS.0000000000004547

30 Contant CM, van Geel AN, van der Holt B, Griep C, Tjong Joe Wai $R$ and Wiggers $\mathrm{T}$ : Morbidity of immediate breast 
reconstruction (IBR) after mastectomy by a subpectorally placed silicone prosthesis: the adverse effect of radiotherapy. Eur J Surg Oncol J Eur Soc Surg Oncol Br Assoc Surg Oncol 26: 344-350, 2000. PMID: 10873353. DOI: 10.1053/ejso.1999.0896

31 Lin KY, Johns FR, Gibson J, Long M, Drake DB and Moore MM: An outcome study of breast reconstruction: presurgical identification of risk factors for complications. Ann Surg Oncol 8: 586-591, 2001. PMID: 11508620. DOI: 10.1007/s10434-0010586-3

32 Krueger EA, Wilkins EG, Strawderman M, Cederna P, Goldfarb S, Vicini FA and Pierce LJ: Complications and patient satisfaction following expander/implant breast reconstruction with and without radiotherapy. Int J Radiat Oncol 49: 713-721, 2001. PMID: 11172953.DOI: 10.1016/S0360-3016(00)01402-4

33 Song J, Zhang X, Liu Q, Peng J, Liang X, Shen Y, Liu H and Li $\mathrm{H}$ : Impact of neoadjuvant chemotherapy on immediate breast reconstruction: a meta-analysis. PLoS One 9: e98225, 2014. PMID: 24878776. DOI: 10.1371/journal.pone.0098225

34 Petersen A, Eftekhari ALB and Damsgaard TE: Immediate breast reconstruction: A retrospective study with emphasis on complications and risk factors. J Plast Surg Hand Surg 46: 344348, 2012. PMID: 22931106. DOI: 10.3109/2000656X. 2012.700025

35 Chang DW, Reece GP, Wang B, Robb GL, Miller MJ, Evans GR, Langstein HN and Kroll SS: Effect of smoking on complications in patients undergoing free TRAM flap breast reconstruction. Plast Reconstr Surg 105: 2374-2380, 2000. PMID: 10845289. DOI: 10.1097/00006534-200006000-00010
36 Padubidri AN, Yetman R, Browne E, Lucas A, Papay F, Larive $\mathrm{B}$ and Zins J: Complications of postmastectomy breast reconstructions in smokers, ex-smokers, and nonsmokers. Plast Reconstr Surg 107: 342-349; discussion 350-351, 2001. PMID: 11214048. DOI: 10.1097/00006534-200102000-00007

37 Paprottka FJ, Schlett CL, Luketina R, Paprottka K, Klimas D, Radtke C and Hebebrand D: Risk factors for complications after skin-sparing and nipple-sparing mastectomy. Breast Care Basel Switz 14: 289-296, 2019. PMID: 31798388. DOI: 10.1159/ 000503218

38 Vanni G, Materazzo M, Pellicciaro M, Morando L, Portarena I, Anemona L, D'angelillo Mr, Barbarino R, Chiaravalloti A, Meucci R, Perretta T, Deiana C, Orsaria P, Caspi J, Pistolese CA and Buonomo OC: Does age matter? estimating risks of locoregional recurrence after breast-conservative surgery. In Vivo 34: 1125-1132, 2020. PMID: 32354901. DOI: 10.21873/ invivo. 11884

Received November 5, 2020

Revised December 1, 2020

Accepted December 2, 2020 